\title{
Erratum
}

\section{Erratum: Scott et al., Wandering Neuronal Migration in the Postnatal Vertebrate Forebrain}

In the article "Wandering Neuronal Migration in the Postnatal Vertebrate Forebrain" by Benjamin B. Scott, Timothy Gardner, Ni Ji, Michale S. Fee, and Carlos Lois, which appeared on pages 1436-1446 of the January 25, 2012 issue, movie captions and stills were incorrectly printed. The corrected movie captions and stills are listed below. Also, there is an incorrect reference to Movie 1 on page 1440, the sentence "The majority of $\mathrm{GFP}^{+}$cells (13 of 14). . (Fig. $3 b$ and Movie S1)." The text "and Movie S1" should be removed. Movie 1 shows data from the experiment described in Figure 5, not Figure 3. The link to Movie 1 should be listed on page 1441 in the first sentence of the first full paragraph “To investigate migratory mechanisms, we acquire. . . 3.5-7 h (Movie 1)." These errors have been corrected in the online PDF version.

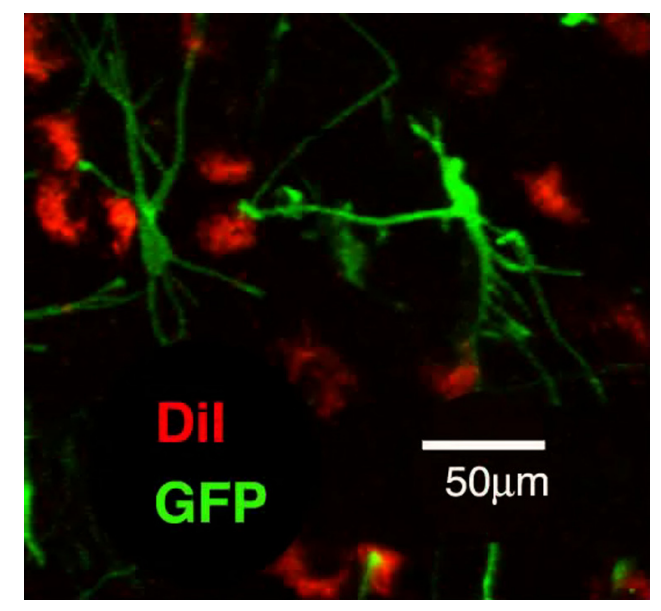

Movie 1. In vivo imaging of neuronal migration in the juvenile zebra finch brain. Time-lapse video of a GFP ${ }^{+}$multipolar cell (green) in HVC over $5.5 \mathrm{~h}$. The somata of $\mathrm{Dil}^{+} \mathrm{HVC}_{\mathrm{x}}$ neurons are shown in red. This migrating cell changes directions twice during the $5.5 \mathrm{~h}$ of imaging shown here. Scale bar represents $50 \mu \mathrm{m}$.

DOI: 10.1523/JNEUROSCI.2172-12.2012

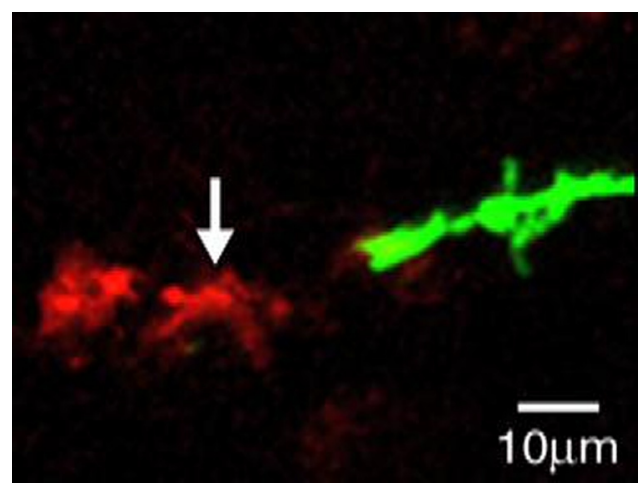

Movie 2. In vivo time-lapse movie of a process tip of a $\mathrm{GFP}^{+}$multipolar cell (green) that makes contact with the somata of a $\mathrm{Dil}^{+} \mathrm{HVC}_{\mathrm{X}}$ neuron (red). Arrow indicates the $\mathrm{HVC}_{\mathrm{X}}$ neuron that is the target of the extending $\mathrm{GFP}^{+}$process. Note the characteristic swelling of the tip of the process during extension. Total elapsed time is $7 \mathrm{~h}$. Scale bar represents $10 \mu \mathrm{m}$. 